\title{
An assessment of the potential for spurring transformational change through Nationally Appropriate Mitigation Actions (NAMAs)
}

\author{
Fridahl Mathias and Linda Johansson
}

Journal Article

\section{Tweet}

N.B.: When citing this work, cite the original article.

Original Publication:

Fridahl Mathias and Linda Johansson, An assessment of the potential for spurring transformational change through Nationally Appropriate Mitigation Actions (NAMAs), Environmental Innovation and Societal Transitions, 2016.

http://dx.doi.org/10.1016/j.eist.2016.11.003

Copyright: Elsevier

http://www.elsevier.com/

Postprint available at: Linköping University Electronic Press

http://urn.kb.se/resolve?urn=urn:nbn:se:liu:diva-133326

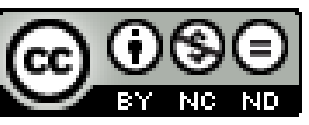




\section{An assessment of the potential for spurring transformational change through Nationally Appropriate Mitigation Actions (NAMAs)}

Mathias Fridahl, Linda Johansson

mathias.fridahl@liu.se

Linköping University, Department of Thematic Studies - Environmental Change

Centre for Climate Science and Policy Research, Sweden

Post-print of article in Environmental Innovation and Societal Transitions, http://dx.doi.org/10.1016/j.eist.2016.11.003

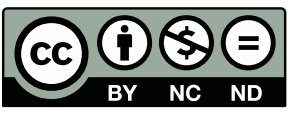

\section{Abstract}

Fulfilling the UN Paris Agreement on climate change requires societal change at transformational scales, with associated challenges that are intensified in developing countries. In this context, Nationally Appropriate Mitigation Actions (NAMAs) - a key instrument in support of developing countries' climate actions - are promoted for their high theoretical transformative potential. However, little is known of how NAMAs are related to transformation in practice. This article studies how developing countries intend to use the instrument to implement climate actions and whether these intentions are related to how transformation can be spurred at landscape, regime, and niche levels. 144 developing countries' Intended Nationally Determined Contributions to the Paris Agreement are examined alongside 17 representative NAMA proposals. Although there is scope to improve consideration of the instrument's theoretically high transformative potential in actual design, current practices indicate that spurring transformational change is already a high priority of NAMA designers.

Keywords: Transformational change; UN Framework Convention on Climate Change (UNFCCC); Nationally Determined Contributions (NDCs); Nationally Appropriate Mitigation Actions (NAMAs); Multi level perspective; Strategic niche managementa. 


\section{Introduction}

The Paris Agreement under the UN Framework Convention on Climate Change (UNFCCC), adopted in 2015, serves to strengthen the international response to climate change through aiming to keep the global temperature rise well below $2{ }^{\circ} \mathrm{C}$, increasing adaptive capacity and resilience, and redirecting finance flows toward climate-resilient development (UNFCCC, 2016). Fulfilling these goals requires no less than societal change at transformational scales (McAlpine et al., 2015). The challenges associated with transformational change towards lowcarbon and climate resilient societies are intensified in developing countries as they struggle to fulfill other immediate policy goals such as poverty eradication, and increased access to energy and healthcare (Amars et al., 2016).

In 2007, the instrument of Nationally Appropriate Mitigation Actions (NAMAs) was established by the UNFCCC to support developing countries' climate actions. The instrument is very inclusive, which has contributed to a broad diversity of initiatives being labeled NAMAs (Coetzee \& Winkler, 2014; Fridahl et al., 2015). The ability to focus on many different types of intervention at several levels in socio-technical systems have led to the instrument being promoted for its high theoretical transformative potential (Lütken, 2015; Mersmann, Olsen, et al., 2014; Mersmann, Wehnert, et al., 2014).

Whereas the theoretical transformative potential of the instrument has been explored in previous literature, little is known of how this potential is reflected in practice. Lack of clarity remains on the extent to which developing countries link NAMAs to their Intended Nationally Determined Contributions (INDCs), which are countries' mandatory climate action plans under the Paris Agreement, and, in particular, whether they relate the instrument to key aspects of transformation. This article assesses whether the instrument's theoretically high transformative potential is reflected in how countries intend to use NAMAs in their future responses to climate change. This article asks how often and in what contexts countries refer to NAMAs in their INDCs, and whether NAMA proposals underpinning INDCs relate to ways of spurring transformational change at landscape, regime, and niche levels.

Section two provides background to NAMAs and how they relate to transformational change. Section three defines the concept of transformational change and discusses how the multilevel perspective (MLP) and strategic niche management (SNM) theories have been used in 
assessing the theoretical potential of the instrument to spur transformation. Section four presents a mixed-methods approach, the results of which are presented in section five. The section starts by quantitatively analyzing whether NAMAs are referred to in all of the developing countries' INDCs available in English $(n=144)$, by which countries and in what contexts. A qualitative analysis of 17 NAMA proposals explicitly or implicitly underpinning the INDCs of eight countries with different income levels enriches the quantitative analysis by applying theories of transformational change in evaluating the design of actual proposals. In section six, the article concludes that, although 45 countries mention the instrument in their INDCs, it is very difficult to draw conclusions about how they intend to use the instrument by studying only their INDCs. The 17 NAMA proposals, however, include both explicit and implicit references to how transformational change can be spurred, indicating that the high theoretical transformative potential ascribed to the instrument may be reflected in design practices.

\section{Background}

Tackling climate change is just one of many tasks that particularly challenge developing countries, which have relatively low capacities to act. To this end, several institutions have been established to support developing countries' climate actions, and these institutions often seek to promote transformations toward low-carbon societies (Mersmann, Wehnert, et al., 2014; Winkler \& Dubash, 2015). At the same time, the means to achieve transformational change need to be adapted to national circumstances (Laes et al., 2014). In this regard, NAMAs have been valued for their flexibility to accommodate national circumstances, particularly as they can be designed to go beyond the project level to induce change in whole sectors or at the national level. This gives the instrument a high theoretical potential to contribute to transformational change.

The instrument was first agreed by the UNFCCC in 2007 as part of the so-called Bali Action Plan, stating that "Nationally appropriate mitigation actions by developing country Parties in the context of sustainable development, supported and enabled by technology, financing and capacity-building, in a measurable, reportable and verifiable manner” (UNFCCC, 2007, §1.b.ii.). Further negotiations on NAMAs - aiming for a new treaty by end of 2009 - were accepted in context of also agreeing to negotiate a shared vision, containing a long-term global goal, and "nationally appropriate mitigation commitments or actions, including 
quantified emission limitation and reduction objectives, by all developed country Parties” (UNFCCC, 2007, §1.b.i.).

In the wake of failing to conclude a treaty in 2009, further agreements related to NAMAs, for example on reporting requirements, were achieved in 2010. However, they provided no additional clarity on how to delineate the scope of actions (UNFCCC, 2011). Within these imprecise limits, diverse climate actions labeled as NAMAs are flourishing, partly as a result of varied national circumstances (Sharma \& Desgain, 2013).

The literature has categorized NAMAs into five types: programmatic, project, policy, plan/strategy, and target (Cocco et al., 2011; De Vit et al., 2012). Historically, the project type has been dominant, often focusing on single sectors. More recently, however, a possible trend toward broader forms of actions has been noted (Fridahl et al., 2015; Lütken et al., 2013). Broader-ranging actions incorporating plans for sustained effects beyond short-term international support have been highlighted as a step in the right direction to tap the instrument's transformative potential (Fridahl et al., 2015; Lütken et al., 2013; Sharma \& Desgain, 2013; van Tilburg et al., 2011).

Peer-reviewed studies of NAMAs have primarily been qualitative and driven by case studies of countries or sectors (Amars et al., 2016; Burns \& Vishan, 2010; Winkler, 2014). Some studies have considered the institutional aspects, such as complexity in accessing or matching support with proposals (Fridahl et al., 2014; Shrivastava \& Upadhyaya, 2014; Winkler \& Dubash, 2015) and the evolution of the instrument (Coetzee \& Winkler, 2014). In addition, a few studies have taken comparative approaches to understanding how the instrument is interpreted across countries and types of actors (Fridahl et al., 2015; Garibaldi et al., 2014; Tyler et al., 2013).

Although the literature includes conceptual research into the instrument's transformative potential, it is largely silent as to how this potential is reflected in developing countries' actual intentions in using NAMAs (Cameron et al., 2015; Day et al., 2015, 2016; Mersmann, Olsen, et al., 2014; Mersmann, Wehnert, et al., 2014). Exploring these intentions through investigating whether NAMAs are linked to INDCs and, if so, considering the contexts in which the instrument is discussed, the types of actions countries refer to, and whether countries explicitly or implicitly address connections between NAMAs and transformational 
change can help shed light on whether and how countries envisage the transformation necessary to reach the goals of the Paris Agreement.

\section{Theories of transformational change}

Change - as part of either incremental development or response to crisis - is inherent to societies. Transformational change thus signifies a measure of scale, i.e. the large-scale and radical change of shifting from an old to a new development path (Scoones et al., 2015).

Theories of transformational change provide a framework for understanding whether and how NAMAs can be designed to spur transformation toward climate and development goals, i.e. as a tool for transition management. Here, the understanding of transformational change draws on the multi-level perspective (MLP) and strategic niche management (SNM), emphasizing system dynamics and deliberate transition management (Elzen et al., 2004; Kemp et al., 1998; Raven et al., 2010). MLP fosters an understanding of the basic components of large sociotechnical systems, highlighting general barriers to and possibilities for promoting transformational change. SNM is more finely grained, giving insight into how smaller parts of the socio-technical systems can be managed to spur the transformational change of sociotechnical configurations.

\subsection{The multi-level perspective and strategic niche management}

In MLP, transformation is seen as entailing interaction between multiple actors at three levels of socio-technical systems, i.e. the regime, niche, and landscape levels (Geels, 2012). The regime is the locus of stability and structure. This includes choices of technology, infrastructure, established practices such as business models, and laws and norms, all of which give rise to various lock-ins. Niches are places of innovation in which new ideas, technologies, and business opportunities are tested; if these innovations are successful, they can alter the system through contributing to regime transformation. The landscape is often described as external to the system and encompasses, for example, international politics and impacts of climate change, factors that are difficult to influence but can affect national or subnational actors (Geels, 2011; Laes et al., 2014; Markard et al., 2012; Mersmann, Olsen, et al., 2014). 
Transformation can be initiated by interaction between actors and different system levels. Initiation can originate, for example, in successful niches that induce change in the regime, from direct landscape pressure on the regime, or through landscape pressure generating cracks in the regime that give rise to niches. MLP emphasizes that transformational change usually results from several factors at several levels that, deliberately or not, work in the same direction (Geels, 2012).

Informed by MLP, Mersmann, Olsen et al. (2014) suggest that three matters are of particular interest when evaluating the transformative potential of NAMAs. First, attention should be paid to the intended scale and direction of change. Ideally, climate mitigation actions should be promoted in relation to goals to which they could contribute. In doing so, the designers of mitigation actions should try to realize existing opportunities and address as many barriers to change as possible, including technological, political, cultural, and economical barriers. If the action can have effects in multiple areas of the system, its chance of generating transformation increases.

Changing the regime - the locus of stability in sociotechnical systems - is often dependent on the accumulation of activities, that operates in the same direction, over relatively long timeframes (Geels and Schot, 2007). Dedicated support for NAMAs, on the other hand, often operates in short timeframes (less than five years); support institutions generally seek to avoid the institutionalization of support (Fridahl et al., 2015). Therefore, in conjunction with studying the intended scale and direction of change, it is also significant to understand if the proposals for mitigation actions include "exit strategies” to assure a lifetime beyond the end of international support.

Second, it is important to evaluate whether a NAMA seeks to develop existing or create new niches. If no active niche exists in which an opportunity for actions has been identified, a proposal could endeavor to establish one. If a niche already exists, a proposal could concentrate on supporting its development or scaling it up, for example, through standardization, environmental tax reform, and other regulations.

Third, a NAMA should ideally be aligned with positive framings in the socio-technical landscape, for example, gaining support through alignment with requirements postulated by international politics or voiced by international support providers. However, in doing so, 
potential discrepancies between what is considered nationally appropriate and requirements of international politics and support institutions may arise, as will be discussed further in section 5.2.3.

According to MLP, most transformations have historically originated in niches (Elzen et al., 2004). How NAMAs relate to niches is therefore of particular interest. Consequently, SNM, as a branch of MLP focusing on niche development, provides a more granular framework for analyzing the instruments' transformative potential (Mersmann, Olsen, et al., 2014; van der Laak et al., 2007). SNM focuses on how best to enhance the market potential of a niche and to induce change dynamics in the niche's regime (Coenen et al., 2010). To this end, SNM highlights three factors that can spur transformation. First, the need for learning processes should be acknowledged. In the process of creating a niche, several barriers usually need to be breached to overcome conservative regime forces. It is important to identify these barriers, which can be done partly through trial and error by testing new technologies. The success of a niche is more likely if the need for such a learning process is explicitly acknowledged (Kemp et al., 1998).

Second, explicit expectations and visions are crucial. In the initial phase of innovation, the benefits of developing a niche are often not clear. Success is spurred if expectations are explicit, framed in positive terms, and highlighted by the involved actors, especially if these expectations are supported by research and the aim is to address a problem in the current regime (Kemp et al., 1998). This overlaps with the MLP view, stressing the importance of positive visions in motivating directly involved actors and in gaining support among a broader community of stakeholders (Geels, 2012).

Third, building strong social networks around niches, involving coalitions of actors formed around common visions, can expand the resources available for developing the niche (Geels, 2012). Governments have a prominent role in determining policy and regulations that support niches and strengthen visions. Nevertheless, other actors, such as grassroots movements and business organizations, are also important to policy formulation and implementation, and their involvement improves the chances that a niche will have sustained impact on the regime (Kemp et al., 1998; Markard et al., 2016). 


\section{Mixed methods: explanatory sequential design}

To answer the research questions, a mixed methods approach was applied. "By definition, mixed methods is a procedure for collecting, analyzing, and 'mixing' or integrating both quantitative and qualitative data ... for the purpose of gaining a better understanding of the research problem” (Ivankova et al., 2006, p. 3). Here, an explanatory sequential approach was selected to advance the understanding of the transformative potential of NAMAs. It does this stepwise, starting with a quantitative analysis of INDCs that builds an informed starting point for the qualitative analysis of a set of selected NAMA proposals (Guest et al., 2012; HesseBiber, 2010; Ivankova et al., 2006).

Although the quantitative analytical phase is essential both in order to gain an overview of how INDCs relate to the instrument and to select relevant cases for qualitative analysis, on the whole, priority is given to the qualitative analysis that brings context and clarity to the results of the quantitative analysis (Ivankova et al., 2006).

\subsection{Quantitative analysis through "key word in context” (KWIC)}

Phase one of the analysis maps the number of references to NAMAs in INDCs, ${ }^{1}$ focusing on the types and purposes of the proposed actions. The previous literature on NAMAs and transformational change stresses that careful choice of type of action, process design, and alignment with national development goals is key to spurring transformational change (cf. e.g. Amars et al., 2016; Fridahl et al., 2015; Lütken et al., 2013). Project and programmatic NAMAs with shorter timeframes are identified as opportunities for niche development, while broader forms, i.e. policy, plan/strategy, and target NAMAs, are often treated as opportunities for developing support structures for niche up-scaling. The broader types of actions could also focus more directly on large-scale regime changes through, for example, incentives, and are described as having a higher theoretical transformative potential.

Focusing here on type of actions provides a broad proxy for the roles that developing countries intend NAMAs to play. Accordingly, a content analysis method, "key word in context” (KWIC), was used to retrieve and analyze the text surrounding references to NAMAs in order to grasp their contexts (Guest et al., 2012). The contexts of references were

\footnotetext{
${ }^{1}$ Search terms: “national/-ly appropriate/-d mitigation action/-s” or “NAMA/-s”.
} 
coded according to the types of actions cited but also according to the process status, i.e. whether countries are planning to use the instrument or have already identified specific proposals for implementation (cf. Table 1). 


\section{Table 1}

Codes used in analyzing references to NAMAs in INDCs.

\begin{tabular}{|c|c|c|}
\hline Theme & Sub-theme & Description \\
\hline \multirow[t]{5}{*}{ Type } & Programmatic & Many small actions bundled together in one proposal \\
\hline & Project & $\begin{array}{l}\text { Single actions in specific sectors with clear targets, often } \\
\text { focusing on infrastructure and machinery }\end{array}$ \\
\hline & Policy & $\begin{array}{l}\text { Actions with nation- or sector-wide scope to promote or } \\
\text { discourage various behaviors through regulation: for } \\
\text { example, tariff systems, taxes, and standards }\end{array}$ \\
\hline & Plan/strategy & $\begin{array}{l}\text { A long-term goal-oriented framework often underpinned } \\
\text { by several actions: for example, a national action plan } \\
\text { covering the most important sectors with defined reduction } \\
\text { targets and timeframes }\end{array}$ \\
\hline & Target & $\begin{array}{l}\text { A sector- or economy-wide target and timetable for } \\
\text { emission reductions }\end{array}$ \\
\hline \multirow[t]{2}{*}{ Status } & Planned usage & $\begin{array}{l}\text { References to actions that countries specify that they will } \\
\text { use or investigate how they can use the instrument without } \\
\text { specifying type(s) }\end{array}$ \\
\hline & Implemented & $\begin{array}{l}\text { References to actions that are under, or ready for, } \\
\text { implementation without specifying type(s) }\end{array}$ \\
\hline Other aspects & & $\begin{array}{l}\text { References that do not concern type or status: for example, } \\
\text { references to lessons learned for drafting climate actions, } \\
\text { finance, or the requirement that the actions should be } \\
\text { measurable, reportable, and verifiable (MRV) }\end{array}$ \\
\hline
\end{tabular}

(Sources: De Vit et al., 2012; Lütken et al., 2013)

The INDCs were retrieved 17 June 2016 from the UNFCCC online repository (www4.unfccc.int/submissions/indc); they comprised 162 INDCs representing 189 countries, ${ }^{2}$ 144 of which are classified as developing countries under the UNFCCC. Nine INDCs from Latin America and Africa excluded due to language barriers were compensated for by large representation of other countries from these regions. Another nine developing country parties to the UNFCCC, distributed across all income categories, have not submitted INDCs.

\footnotetext{
${ }^{2}$ The EU submitted a common INDC for all its 28 member states.
} 


\subsection{Qualitative thematic analysis utilizing theories of transformational change}

Phase two of the analysis conducts a qualitative thematic analysis of NAMAs (cf. Guest et al., 2012). Table 2 summarizes how MLP and SNM are used to structure the search for themes relevant to transformational change, expressed both explicitly and implicitly in the NAMA proposals. 


\section{Table 2}

Analytical framework for analyzing NAMA proposals.

\section{System level}

Questions about the material

MLP
SNM

\begin{tabular}{lll}
\hline $\begin{array}{l}\text { Entire socio- } \\
\text { technical system }\end{array}$ & $\begin{array}{l}\text { To what scale of change (i.e. } \\
\text { landscape, regime, and/or niche } \\
\text { levels) are the actions intended to } \\
\text { contribute? }\end{array}$ & - \\
Landscape & $\begin{array}{l}\text { Are the actions aligned with } \\
\text { opportunities to gain legitimacy } \\
\text { from landscape pressure? }\end{array}$ & - \\
Regime & $\begin{array}{l}\text { Are the actions designed to address } \\
\text { barriers to change in the regime? }\end{array}$ & $\begin{array}{l}\text { Does the NAMA proposal } \\
\text { articulate a clear goal and relate it } \\
\text { to solving a problem in the regime? }\end{array}$ \\
Niche & $\begin{array}{l}\text { Are the actions designed to develop } \\
\text { existing or create new niches? }\end{array}$ & $\begin{array}{l}\text { Does the proposal include } \\
\text { opportunities to learn about barriers } \\
\text { to and drivers of the uptake of low- } \\
\text { carbon niches by the regime? }\end{array}$ \\
& & $\begin{array}{l}\text { Does the proposal provide } \\
\text { opportunities to create supportive } \\
\text { social networks? }\end{array}$ \\
\hline
\end{tabular}

Seventeen proposals from eight countries were selected based on the criteria that at least one proposal cited in the country's INDC should be publically available, that countries from all income levels should be represented in the sample, and that the case countries should be representative of their income class in terms of the themes covered in their intentions to use NAMAs expressed in the INDCs identified in the quantitative analysis.

Income is arguably a good proxy for capacity to design NAMAs, with low-income countries being more likely to design project proposals and high-income countries having a higher capacity to take on broader types of actions, such as policy or strategy (Fridahl et al., 2015; Sharma \& Desgain, 2013). World Bank data on income levels and classifications are applied, expressed in USD gross national income (GNI) per capita and categorized into low- ( $\leq 1025)$, lower-middle- (1026-4035), upper-middle- (4036-12475), and high- $(\geq 12476)$ income countries (World Bank, 2016). Two countries from each income level were selected (cf. Table 3), enabling comparative study. 


\section{Table 3}

Selected case countries.

\begin{tabular}{llc}
\hline $\begin{array}{c}\text { Income level } \\
\text { (World Bank, 2016) }\end{array}$ & \multicolumn{1}{c}{ Country } & $\begin{array}{c}\text { No. of NAMA } \\
\text { proposals studied }\end{array}$ \\
\hline High & Barbados & 1 \\
\multirow{2}{*}{ Upper-middle } & The Cook Islands & 1 \\
& Costa Rica & 3 \\
Lower-middle & Georgia & 3 \\
& Tunisia & 2 \\
Low & Lao People's Democratic Republic & 3 \\
& Bangladesh & 2 \\
& The Gambia & 2 \\
\hline
\end{tabular}

The 17 proposals were collected on 23 March 2016 from three sources: the UNFCCC NAMA Registry (NR, www4.unfccc.int/sites/nama), the NAMA Database (ND, www.namadatabase.org), and the Transport NAMA Database (TND, www.transport-namadatabase.org).

The NR is a platform to which countries can submit domestically supported NAMAs for recognition or proposals seeking international support. The two databases are maintained by Ecofys and store information on initiatives formally labeled NAMAs, with the TND focusing specifically on the transport sector. Some NAMAs are listed exclusively in one source but not another. The sources are complementary, offering the prospect of covering a substantial share of initiatives globally. NAMAs in the NR are cited by ID number whereas actions listed in the two databases are cited by web address. If a proposal appears in multiple repositories, the NR listing was prioritized, as it often includes more information and has a higher official status.

\subsection{Methodological limitations}

Several methodological limitations should be duly noted. First, there are reasons to believe that processes of designing INDCs were sometimes based on patching together available pieces of the mitigation architecture with little consideration of actual implementation. Although it is hard to find support for this in the peer reviewed literature, the KWIC analysis should be understood in this context, i.e. that the INDCs alone is not offering a sufficient evidence base for concluding on how NAMAs relate to ways of spurring transformational change. The KWIC analysis should therefore primarily been seen as a way of answering how 
often and in what contexts countries refer to NAMAs in their INDCs, on which basis a selection of more detailed NAMA proposals are made for further analysis.

Second, of the nine non-English INDCs excluded from analysis, at least Côte d'Ivoire, the Democratic Republic of the Congo, and El Salvador refer to NAMAs (compare Table 4). However, language barriers prevented the analysis of in what context these references are made. They are therefore excluded from the KWIC analysis. The effects on the results are assessed as likely to be small since these three countries are distributed across the low- and middle-income categories, categories in which they would make marginal contributions to the overall results. If high-income countries would have been excluded from analysis, the effects could potentially have been larger.

Third, not all activities labelled as NAMAs are likely to appear in the Registry or the Databases. Although access to information on NAMAs that do not appear in these repositories is often restricted, the reader should be aware of this potential selection bias.

Fourth, even if a NAMA proposal relates to how transformation can be spurred, the data do not allow clear conclusions on the drivers behind including such discussions. As discussed further in section 5.2.3, it is plausible, for example, it could be the result of attempts to fulfil support providers' expectations rather than strategic ambitions to spur transformation. This article therefore primarily assesses weather NAMAs relate to ways of spurring transformational change rather than why.

\section{Results and discussion}

\subsection{References to NAMAs in INDCs}

A total of 38 of the countries refer to NAMAs in their INDCs; all of these countries are classified as developing countries according to the UNFCCC (Table 4). 


\section{Table 4}

Countries referring to NAMAs in their INDCs.

\begin{tabular}{ccc}
\hline & Country & \\
\hline Afghanistan & Georgia & Republic of Moldova \\
Armenia & Ghana & Rwanda \\
Bangladesh & Guinea & Seychelles \\
Barbados & Jordan & Sierra Leone \\
Belize & Lao & Sri Lanka \\
Botswana & Malawi & St. Vincent and the \\
Burkina Faso & Madagascar & Tonadines \\
Cabo Verde & Marshall Islands & Tunisia \\
Chile & Mongolia & Turkmenistan \\
The Cook Islands & Namibia & Vanuatu \\
Costa Rica & Niger & Vietnam \\
Eritrea & Nigeria & Zambia \\
The Gambia & Palau & \\
\hline
\end{tabular}

These 38 countries mention NAMAs 154 times, referring to 79 individually distinct proposals. Most references are made in the context of the process status (i.e. proposals under planning, ready for implementation, or already under implementation) rather than type. Many references are also made in other contexts, usually the importance of lessons learned through NAMAs when drafting INDCs (Figure 1). 


\section{Figure 1}

Number of individually distinct NAMAs referred to in INDCs by coding theme.

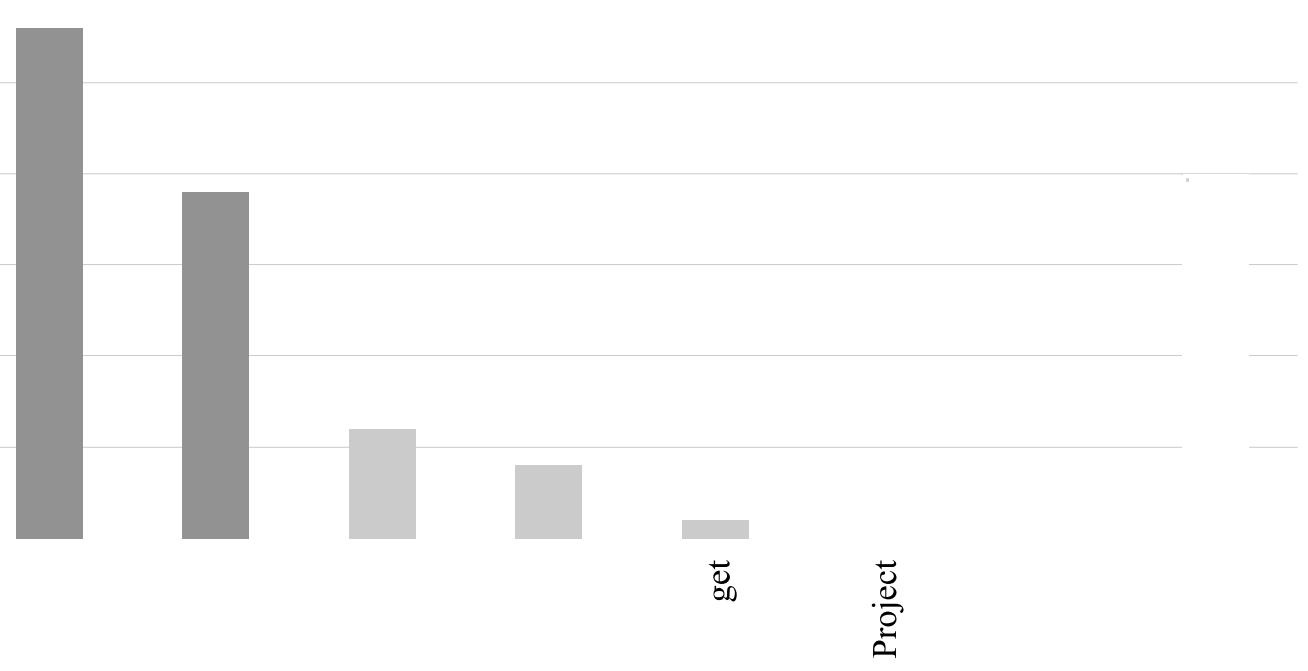

Excluding the "Other" category, references are made to 61 distinct proposals. Of these, 46\% refer to plans to use the instrument in implementing INDCs and another 31\% refer to actions already under implementation or considered ready for implementation pending support. Only a few references are made in contexts that specify the type of actions $(n=11)$, of which $55 \%$ refer to strategy/plan, 36\% to policy, and 9\% to target NAMAs. References to project and programmatic NAMAs, often discussed in the literature, are not explicit in INDCs. Previous research has emphasized that the most common NAMAs are of project type (Fridahl et al., 2015; Lütken et al., 2013). As most references lack clarity as to type, this could also be the case for the actions referred to in INDCs. However, in cases in which clarity exists, the INDCs do not refer to project proposals.

While countries explicitly do intend roles for their NAMAs in relation to their NDCs, the lack of clarity as to the types of actions that countries have in mind makes it difficult to draw any conclusions without analyzing additional sources of information. Referring to plans to use the instrument, but without specifying how, keeps the option of using it open while not being strongly committed. This could imply that countries are still uncertain as to how the 
instrument can help them meet their pledges. Another plausible explanation is uncertainty related to the level or availability of international support.

Note that this lack of clarity could mean that several other countries plan to use NAMAs but do not mention this in their INDCs due to uncertainty as to how to specify the role of the instrument. Many scholars emphasize that the UNFCCC's vague definition of NAMAs is advantageous, as it encompasses a broad range of actions; however, they caution that this vagueness could also be problematic, as it could hinder some countries from proposing proposals for actions (cf. Fridahl et al., 2015; Linnér \& Pahuja, 2012). In fact, several countries that do refer to NAMAs in their INDCs have a track record of previous engagement with the instrument (cf. Day et al., 2015). These countries may have a clearer understanding of how NAMAs could be related to NDCs without wanting, at this stage, to specify its exact type or function.

\subsubsection{References to NAMAs by income classification}

Sharma and Desgain (2013) note that the socio-economic classification of a country could affect NAMA design. Country income is correlated with the number of INDCs that refer to NAMAs (Figure 2): 63\% of all INDCs that refer to NAMAs originate from low- $(n=11)$ or lower-middle-income $(n=13)$ countries, i.e. in total 24 of the 38 relevant INDCs. In addition, of the 61 individually distinct NAMA proposals reported on in Figure 1 (excluding the category “Other”), 61\% originate from low- and lower-middle income countries. However, no correlation can be detected between income classification and type of actions referred to. 


\section{Figure 2}

References to NAMAs in developing countries’ INDCs.

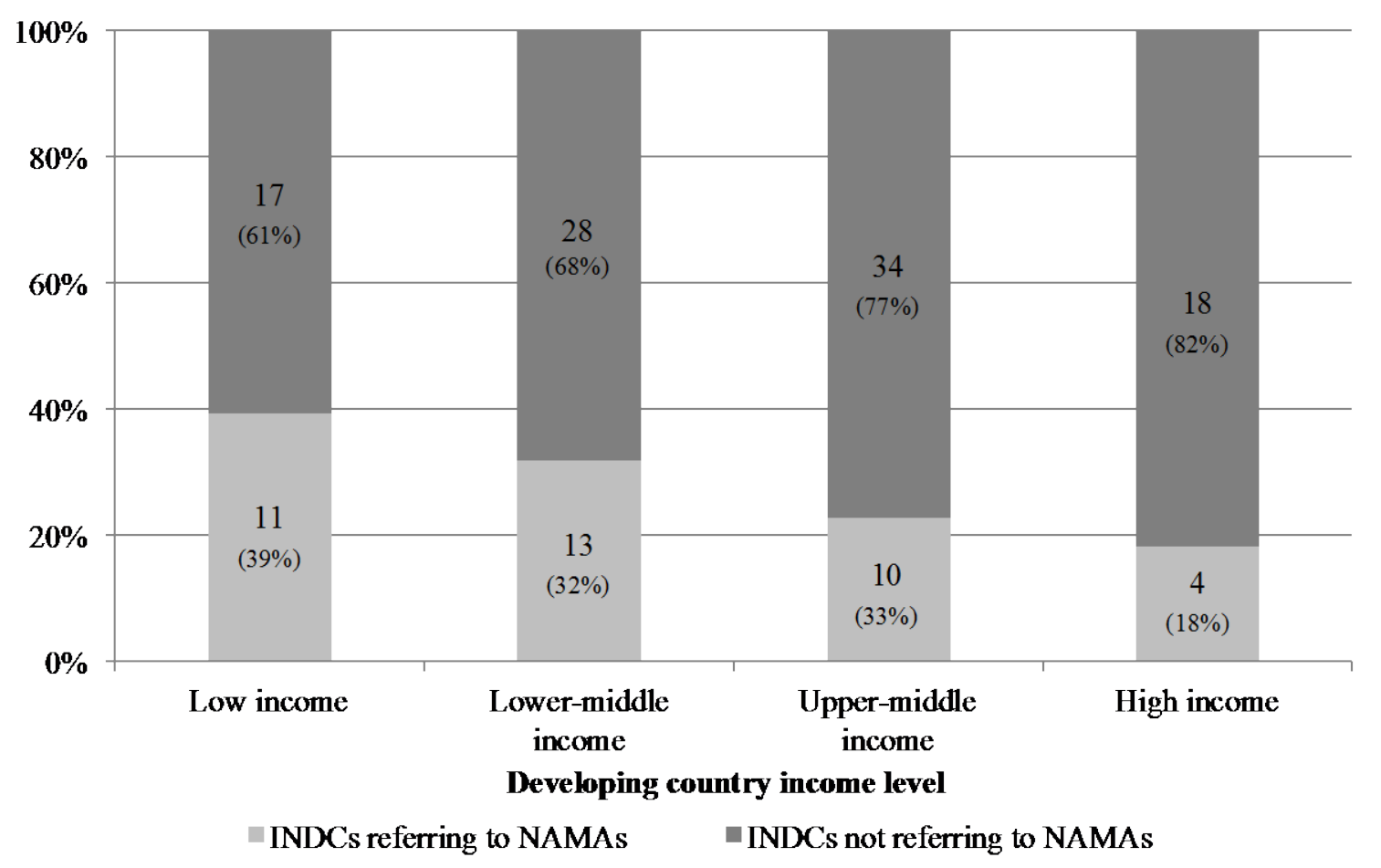

This indicates that the instrument's relevance to countries increase with decreasing income, which in perspective of the possibility it offers for receiving international support seems quite logical. This correlation may also be explained by the tendency among least developed countries, all of which are classified as low-income countries, to use action rather than target based INDCs. As shall be evidenced below, NAMAs are currently associated more with actions than with targets. The instrument, therefore, may be more relevant to action based INDCs. In fact, many countries that submitted target based NAMAs around year 2010 have now instead submitted target based INDCs. No further correlations could be detected based only on INDC data.

5.2. Case study of NAMA proposals underpinning INDCs in developing countries with different levels of income

\subsubsection{Scale and goal of change}

Both SNM and MLP underscore the importance of providing clear visions and goals in order to spur transformational change. Most proposals aim explicitly to spur sector-wide transformation. The following example is illustrative: "The vision for Costa Rican livestock 
in the medium term (10-15 years) is to have an intensified, environmentally sustainable, more modernized and more efficient sector in meat and milk production ... Regarding the Livestock NAMA, the objective of the country is to produce a transformational change in the production and processing forms of the livestock sector” (NR, NS-71, see also NS-201). Some countries, such as Georgia, have even broader goals: "The objective of the NAMA is to foster climate resilient, low-carbon, sustainable rural development and poverty reduction” (NR, NS-229), i.e. the transformation of much of Georgia's socio-technical regime. Another example of an ambition for radical change of the socio-technical regime through NAMAs is provided by Lao PDR: "It [i.e. the NAMA] is embedded in national climate, transport and development policy, and the potential for replication has been considered, thereby underscoring its potential to have a transformational impact” (TND, n.d.1).

In general, the goals to which the actions proposed should contribute are clearly articulated and often related to development goals (for example: TND, n.d.2; ND, 2014b). The scale of change is also envisioned. A few countries even aim to spur change at the landscape level. As expressed by Costa Rica, its proposed mitigation actions "will allow changing the perspective in the Costa Rican agriculture sector and also in other countries in the region and on an international level on the production of low carbon coffee” (NR, NS-72).

Among the references to NAMAs in INDCs where the type could be identified, the broader types of actions (policy and strategy/plan) were the most common. When looking at actual proposals, some project proposals could be identified, though most were designed as policy or plan/strategy NAMAs. Some researchers (e.g. Fridahl et al., 2015; Lütken et al., 2013) have identified a shift away from project proposals towards broader forms of actions. Further evidence of this shift is provided by this study. This trend could also mean that more of the instrument's transformative potential could be tapped: previous research has stressed that broad NAMAs have higher transformative potential than do more narrowly defined proposals (Fridahl et al., 2015; Lütken et al., 2013).

Many NAMAs studied here were also designed in phases, with a distinct project phase to create protected niches and a policy or strategy phase during which to shape more conducive environments for the niche to become part of the regime, providing scope to spur transformation. In other instances, action on project level is used to pilot a policy or strategy NAMA in a more constrained setting (cf. e.g. NR NS-85, NS-228; ND, 2014a). Most countries have also treated regulatory actions as part of their proposals, in line with Kemp et 
al.'s (1998) suggestion that supportive regulatory actions are key to successful system change (see also Markard et al., 2016). The Cook Islands, for example, are seeking support both to build local capacity to install renewable energy hardware and to develop sector-wide polices (NR, NS-48). The combined actions targeting different levels of socio-technical systems found in the proposals studied here are not easily classified using existing typologies proposed by, for example, De Vit et al. (2012), and are therefore, in this article, referred to as "hybrid NAMAs."

These hybrid forms of actions could possibly tap more of the transformative potential of NAMAs because they focus on a spectrum of initiatives and simultaneously target various system dimensions, protecting niches, developing know-how, and proposing broad policy or strategy in support of the niche. Previous literature also suggests that countries' capacity to act may be correlated with patterns of NAMA design, for example, with a preference for project actions in low-income countries (Fridahl et al., 2015; Sharma \& Desgain, 2013). However, no correlation between the types of actions proposed and income level could be noted in the 17 proposals studied here.

These examples all display clear transformative ambitions, though it is also possible to conclude that they are not uniform. Variation in goals and in the proposed interventions at different socio-technical system levels leads to different forms of envisioned or implied transformations, and different forms of transformative potentials, because the proposals relate to different aspects described in theories of transformation. Still, transformation is the intended scale of change, and low-carbon and climate-resilient development constitutes at least part of the goal of change in all countries' NAMA proposals, whether implicitly or explicitly.

\subsubsection{Niche development and/or intensification}

MLP stresses that whether a NAMA focuses on creating new or intensifying existing lowcarbon niches is central to understanding its transformative potential. Most studied countries mention innovations or technology shifts in some form or other, a substantial proportion of which can be considered as actions developing a niche, exemplified by a Bangladesh proposal: "Locally produced heat recovery systems will be piloted at two steel factories, which will capture lost heat from steel melting furnaces and reuse the energy to preheat incoming scrap” (ND, 2015a). 
In SNM, it is argued that several process-related aspects are significant for designing interventions intended to develop or intensify niches, one of which is to allow learning by trial and error. The above Bangladesh example allows such learning processes. If successful, the pilot technology could become part of the regime in which brick production is the fastest growing industrial sector (Guttikunda et al., 2013). Several other NAMAs are designed along similar lines. Another example from The Gambia is the introduction of improved cooking stoves: "The programme will train four people to produce improved cooking stoves, and subsidize their costs by $\$ 7$ per unit in order to popularize their update and distribution” (ND, 2015b). These approaches can be compared with what Caniëls and Romijn (2008) describe as protecting and supporting a developing niche through creating know-how and supporting technology development to become marketable, so as to boost the prospects of the technology succeeding in the regime once subsidies are lifted.

Countries other than Bangladesh and The Gambia have also made proposals to develop niches through NAMAs. The Cook Islands, for example, suggests using a NAMA to replace diesel generators with off-grid renewable energy production, a technology shift spurred by developing a new niche (NR, NS-48). Tunisia seeks to change "behaviours of actors in the building sector by creating new markets niches for energy efficiency and renewable energy in the sector" (ND, 2015c). However, these four examples differ in the scale of change proposed and type of NAMA suggested. The Cook Islands and Tunisia aim at total replacement, while The Gambia is initially targeting 200,000 stoves and Bangladesh is targeting two pilot plants. Other cases mention the possibility of inducing change at the landscape level. One example is a Costa Rican proposal: "The first coffee NAMA worldwide could also be an example for mitigation actions to the entire coffee sector in Latin America and worldwide” (NR, NS-72). Many proposals relate to niche development, though the scale of change that they seek to induce in the regime and/or landscape, as an outcome of the niche development, differs.

Many of the proposals cited above also allow what Kemp et al. (1998) describe as assessing innovations by trial and error, both to test for success and learn about barriers to it. Another example of this is presented by Georgia: "This NAMA then paves the way for a second phase to extend the process to the residential sector once the majority of barriers are removed and the country has more experience with the implementation of full building refurbishment, rehabilitation and maintenance” (NR, NS-228). Mapping the benefits of and barriers to an innovation is part of a learning process and an important step in transformation. This is part of 
what Mersmann, Olsen et al. (2014) describe as a key step in initiating transformation, after which scaling up by making a protected niche competitive on the market is the next step. Although Coenen et al. (2010) describe scaling up as inherently difficult, several of the countries relate their development of niches to the possibility of later scaling up actions to induce changes at the regime level.

Another vital component for functionality and for tapping the transformative potential of NAMAs is national support. Structures in the country serving as a support system, such as policy or law, are significant. References to such support systems were found in most studied proposals. One example is from Lao PDR: "The government can build on the existing policy framework, which targets the implementation of various policies, plans and actions aimed at mitigating GHG [i.e. greenhouse gas] emissions while achieving sustainable development, so as to define a comprehensive and coherent NAMA development framework” (NR, NS-227). Another example is provided by Costa Rica: “The NAMA Low Carbon Coffee Costa Rica fits in the National Strategy for Climate Change (ENCC) as well [as] in the agriculture sector strategy” (NR, NS-72). As governments are involved in the design of all studied proposals, the issue of weak governmental support is not as prominent as it can be in some non-state initiatives.

Without regulatory support systems for niches, innovations are less likely to be scaled up, i.e. to have transformative effects (Mersmann, Olsen, et al., 2014). As mentioned above, hybrid NAMAs combining, for example, project activities with supportive policy, could be found in the material. Mersmann, Olsen et al. (2014) state that a NAMA can be designed to target either niche development or policy introduction. However, in the case of hybrid NAMAs, both are taken on under the same umbrella, often in phased approaches starting with niche development and progressing to policy introduction to help scale up niche activities. The proposal from the Cook Islands to develop a niche for off-grid renewables also includes regulatory elements, referring, for example, to using international support to introduce "policy assistance for new legal and regulatory frameworks” (NR, NS-48). This is another example of targeting a support system to underpin the success of the niche component of the NAMA.

Another feature of the proposals, in line with theory on how to spur transformation, is their explicit aim to address perceived problems in the regime. Most proposals describe a need for a shift towards sustainable regime configurations, related not only to climate change 
mitigation but also to other highly prioritized development goals. The latter, such as poverty eradication and improved health, are often key to securing national support for NAMAs in developing countries (Amars et al., 2016). One proposal from Barbados, for example, aims to promote renewable energy and energy efficiency, “thus reducing the country’s dependency on imported fossil fuels, enhancing security and stability in energy supply, and improving overall environmental sustainability” (ND, 2015d).

Focusing on problems in the regime is also useful for building strong social networks, as they can be seen as windows of opportunity for niche development that are often visual and public, making it easier to gain public support (Geels, 2012). Many countries also explicitly mention the importance of maintaining existing and/or striving to build new social networks. Costa Rica lists "collaboration of public and private stakeholders and the civil society" as one factor that "has enabled many successful transformational processes" (NR, NS-72). From the perspective of transformational change, designing participatory processes encourages the building of strong social networks that, in turn, significantly increase the chances that the interventions will have transformational impacts (Kemp et al., 1998; Mersmann, Olsen, et al., 2014). In this regard, awareness raising and knowledge sharing are keys to promoting niches as positive system interventions in broader social networks. Such features could also be found in many of the studied proposals. The Gambia says that "training sessions will be held and awareness will be raised” (NR, NS-226) and that "information leaflets, and television and radio programmes will increase public awareness” (ND, 2015b).

Spreading knowledge of the benefits of an innovation is central to its success, especially if it involves many implementing agents or requires the support of many end users. However, as Geels (2012) has noted, the benefits of innovations are not always clear in the beginning. Therefore, visions and expectations are important motivators as well as significant for building support. All the studied NAMAs include long-term visions. Tunisia, for example, says that its NAMA will "deliver sustainable development co-benefits and reinforce the Tunisian energy sector" (ND, 2015c), while Georgia describes its NAMA as a "model for improved sustainable management of forests, adaptation to climate change, promotion of cobenefits (such as biodiversity protection, poverty alleviation and improving the livelihood and resilience of local communities)” (NR, NS-85). 
In sum, most studied countries refer to developing new niches, supporting existing niches, or both. All three elements of SNM - learning processes, expectations and visions, and social network building - can be found in the studied proposals, although not all aspects are part of all proposals. This indicates that the theoretical transformative potential, at the level of niches, is reflected in the actual practice of designing NAMAs.

\subsubsection{Alignment with landscape pressure}

According to MLP, another key to understanding transformative potential is knowing whether or not the socio-technical landscape is factored into NAMA design. Climate change as such exerts obvious pressure on countries to act, for example, by designing NAMAs. All proposals studied here, unsurprisingly, are aligned with increasing concern about climate change impacts and with the need to act. However, the landscape pressure exerted by international politics is slightly more complex. Clarity on how to define NAMAs is currently lacking at the international level (Coetzee \& Winkler, 2014; Linnér \& Pahuja, 2012). Sharma and Desgain (2013) claim that this could be advantageous as a more precise definition could hinder some countries from developing proposals, and the current vagueness grants high interpretative flexibility to institutions supporting NAMAs. NAMA designers are circumscribed, for better or worse, by support institution willingness to support certain types of actions and not others. Support providers often explicitly aim to encourage transformation towards low-carbon regime configurations through their support, specifying eligibility criteria to steer NAMAs in this direction (Lütken, 2015; Mersmann, Wehnert, et al., 2014; Winkler \& Dubash, 2015; Amars et al., 2016; Fridahl et al., 2014, 2015; Winkler \& Dubash, 2015). As such, landscape pressure on the regime exists despite a very flexible UNFCCC definition of NAMAs stressing that actions should be "nationally appropriate.” The proposals studied here often acknowledge this, their designs being aligned with many requests to consider the transformational potential of NAMAs. Based on the material studied here, it is not possible to conclude whether the relationships between NAMAs and ways to spur transformational change are an effect of landscape pressure in shape of support institutions' criteria or not. What is clear, however, is that such landscape pressure exists. The landscape pressure favoring NAMAs with transformational reach is partly translated into a preference towards lending support primarily to policy NAMAs with sectorial or national reach (Fridahl et al., 2015). This provides a plausible, although tentative, explanation as to why references to programmatic or project NAMAs - as reported in section 5.1 - are relatively few. In light of increasing public concern about climate change, this alignment with landscape pressure is purely positive for building 
social networks in support of NAMAs, though this must often be balanced against or described as synergetic with other development priorities to gain governmental support (cf. Amars et al., 2016).

A few caveats should also be mentioned. First, current NAMAs - in the sample studied here often lack convincing narratives about how their actions will be sustained after support ends (Lütken, 2015). It has been suggested that support providers are reluctant to grant long-term support, fearing that institutionalizing support will limit the leverage of interventions because support cannot be scaled up and maintained to impact the regime level and because such institutionalization would limit the possibility of using the limited available support, over time, to promote a broad set of interventions (Fridahl et al., 2015). If a proposal seeking international support cannot demonstrate how its actions will be sustained or have effects after support ends, it is unlikely to attract funding. Many NAMAs have potential for sustained impacts, yet they are not always explicit about the mechanisms to ensure such impacts which is key information for support providers. However, as Hansen and Nygaard (2013) intimate, calls for longer-term support are nevertheless valid. Such support would allow for more time and permit the inclusion of more components relevant to transition management in individual NAMAs, allowing them to build networks and take trial and error action while maintaining a common goal among involved actors.

Second, there is also scope, in many NAMAs, to frame their transformative potential more clearly and explicitly. Quite aside from the need to ensure sustained actions, transformative potential is of particular interest to support providers. As is highlighted in theories of transformational change, this does not mean that actions should be uniform across the world. Several key aspects, not least procedural ones, can help spur transformational change, though exactly which of these procedural aspects and, more importantly, how to fill these with content should reflect national circumstances (Laes et al., 2014). Winkler and Dubash (2015) fear that transformational change may be defined for developing countries through landscape pressure dominated by influential support institutions. This can potentially be countered if NAMA designers also explicitly reflect the arguments available in theories such as MLP and SNM that transformational change is best spurred if interventions are aligned with long-term goals and visions that have high domestic support. This is not to say that aligning their narratives with support institutions' calls for transformational change with a strong focus on 
climate mitigation is wrong, merely that there is support in MLP and SNM also for alignment with other priorities.

\section{Conclusions}

Nationally Appropriate Mitigation Actions (NAMAs) are referred to 154 times, by 38 countries, in their Intended Nationally Determined Contributions (INDCs) to the new UN climate agreement. 79 NAMAs are discussed in these INDCs, 61 of which are already under implementation or intended to be used in implementing INDCs. The share of INDCs referring to NAMAs is highest in low-income countries, declining with increasing income. The instrument are therefore considered more relevant to countries with less capacity to act, if this capacity is proxied by gross national income/capita. Other than that, and unlike hypotheses introduced in previous literature (cf. Fridahl et al., 2015; Sharma \& Desgain, 2013), this study demonstrates that even though countries' capacities to act are correlated with their willingness to engage with NAMAs, they are uncorrelated with patterns in actual design of proposals for action, at least not in terms of how these proposals relate to transformational change.

However, NAMAs are referred to mostly in contexts that make it difficult to understand the details of how developing countries intend to use the instrument. $45 \%$ of all such references occur in the context of plans to use NAMAs, though without specifying how. Another $31 \%$ of the references relate to actions that are ready for or already under implementation, though these references are also unclear as to the type of actions cited. Only 18\% of the references are to specific types of NAMAs. This lack of clarity makes it difficult to draw conclusions about the instrument's transformative potential based only on information provided in INDCs.

When studying the NAMA proposals that underpin INDCs, it is much clearer that the instrument showcases elements with high transformative potential. The 17 proposals studied here make both explicit and implicit connections to significant aspects of spurring transformational change. These NAMAs seek to develop new low-carbon niches or to develop policy or strategy supporting the scaling-up of existing niches in the socio-technical regime. In some cases, the intention is even to impact the broader socio-technical landscape. Several proposals also relate to the importance of building networks and aligning actions with development strategies, all of which are described, in theory, as key to spurring transformational change. 
The present results also suggest that a shift from actions focusing on single projects to broader forms of NAMAs, such as policy and strategy NAMAs, may be ongoing. The latter have been singled out as having higher transformative potential than the former, though the proposals studied here often also embed project activities under a single umbrella of policy and strategy development. These hybrid NAMAs are promising from a transformation perspective, as the chance of spurring transformational change is higher if change is induced at multiple levels of socio-technical systems.

Although there is scope to improve how the instrument's theoretically high transformative potential is reflected in actual NAMA design, current practices indicate that spurring transformational change is already at least partly addressed in how actions are designed. If this potential is realized in actual implementation remains to be seen. There is a risk that many NAMAs relate to transformation at design level yet that they, in practice, are not integrated into national and, in particular, sectorial policy, but are rather treated as add on activities. If design is further improved, NAMAs - as discussed in INDCs and in the more detailed NAMA proposals that underpin INDCs - can partly realize the instrument's transformative potential, yet it is still too early to assess if the indicative transformative potential expressed through design of NAMAs materialize in actual implementation.

\section{Acknowledgements}

We thank Mattias Hjerpe and two anonymous reviewers for comments that greatly improved the manuscript. This workwas supported by the Swedish Energy Agency grant no. P35462-2.

\section{References}

Amars, L., Fridahl, M., Hagemann, M., Röser, F., Linnér, B.-O., 2016. The transformational potential of Nationally Appropriate Mitigation Actions in Tanzania: assessing the concept's cultural legitimacy among stakeholders in the solar energy sector. Local Environment (online first; DOI: 10.1080/13549839.2016.1161607).

Burns, P. M., Vishan, I., 2010. The Changing Landscape of Climate Change: NAMAs, SIDS and Tourism. Tourism and Hospitality Planning \& Development, 7(3), 317-328.

Cameron, L., Harms, N., Tilburg, X. v., Gardiner, A., Fridahl, M., Davis, S., . . V Vener, J., 2015. NAMAs and INDCs: Interactions and opportunities. Patten and Cologne: Energy Recerach Centre \& Ecofys.

Caniëls, M. C. J., Romijn, H. A., 2008. Actor networks in Strategic Niche Management: Insights from social network theory. Futures, 40(7), 613-629.

Cocco, M., Kollmus, A., Puhl, I., Sutter, C., 2011. How to develop a NAMA by scaling-up ongoing programmatic CDM activities on the road from PoA to NAMAs. Frankfurt am Main: South Pole. 
Coenen, L., Raven, R., Verbong, G., 2010. Local niche experimentation in energy transitions: A theoretical and empirical exploration of proximity advantages and disadvantages. Technology in Society, 32(4), 295-302.

Coetzee, K., Winkler, H., 2014. The international policy context for mitigation actions. Climate and Development, 6(S1), 4-11.

Day, T., Röser, F., Kurdziel, M., 2016. Conditionality of Intended Nationally Determined Contributions (INDCs). Cologne: NewClimate Institute.

Day, T., Röser, F., Tewari, R., Kurdziel, M., Höhne, N., 2015. Preparation of Intended Nationally Determined Contributions (INDCs) as a catalyst for national climate action. Cologne: NewClimate Institute.

De Vit, C., Escalante, D., Röser, F., Jung, M., Höhne, N., 2012. Building blocks for Nationally Appropriate Mitigation Actions. Cologne: Ecofys.

Elzen, B., Geels, F. W., Green, K. (Eds.), 2004. System Innovation and the Transition to Sustainability: Theory, Evidence and Policy. Cheltenham \& Northampton MA: Edward Elgar Publishing.

Fridahl, M., Hagemann, M., Röser, F., Amars, L., 2015. A comparison of design and support priorities of Nationally Appropriate Mitigation Actions (NAMAs). The Journal of Environment \& Development, 24(2), 237-264.

Fridahl, M., Upadhyaya, P., Linnér, B.-O., 2014. Supporting Nationally Appropriate Mitigation Actions through the Green Climate Fund: Governance Capacities and Challenges. Carbon \& Climate Law Review, 8(4), 257-269.

Garibaldi, J. A., Winkler, H., Rovere, E. L., Cadena, A., Palma, R., Sanhueza, J. E., . . . Gunfaus, M. T., 2014. Comparative analysis of five case studies: commonalities and differences in approaches to mitigation actions in five developing countries. Climate and Development, 6(S1), 59-70.

Geels, F. W., Schot, J., 2007. Typology of sociotechnical transition pathways. Research Policy, 36, 399-417.

Geels, F. W., 2011. The multi-level perspective on sustainability transitions: responses to seven criticisms. Environmental Innovation and Societal Transitions, 1(1), 24-40.

Geels, F. W., 2012. A socio-technical analysis of low-carbon transitions: introducing the multi-level perspective into transport studies. Journal of Transport Geography, 24, 471482.

Guest, G., MacQueen, K. M., Namey, E. E., 2012. Applied Thematic Analysis. London: Sage.

Guttikunda, S. K., Begum, B. A., Wadud, Z., 2013. Particulate pollution from brick kiln clusters in the Greater Dhaka region, Bangladesh. Air Quality, Atmosphere \& Health, 6(2), 357-365.

Hansen, U. E., Nygaard, I., 2013. Transnational linkages and sustainable transitions in emerging countries: Exploring the role of donor interventions in niche development. Environmental Innovation and Societal Transitions, 8, 1-19.

Hesse-Biber, S. N., 2010. Mixed methods research: Merging Theory with Practice. New York: Guilford Press.

Ivankova, N. V., Creswell, J. W., Stick, S. L., 2006. Using Mixed-Methods Sequential Explanatory Design: From Theory to Practice. Field Methods, 18(1), 3-20.

Kemp, R., Schot, J., Hoogma, R., 1998. Regime shifts to sustainability through processes of niche formation: The approach of strategic niche management. Technology Analysis \& Strategic Management, 10(2), 175-198.

Laes, E., Gorissen, L., Nevens, F., 2014. A Comparison of Energy Transition Governance in Germany, The Netherlands and the United Kingdom. Sustainability, 6(3), 1129-1152.

Linnér, B.-O., Pahuja, N., 2012. A Registry of Nationally Appropriate Mitigation Actions: Goals, Outcomes, and Institutional Requisites. Ambio, 41(1S), 56-67. 
Lütken, S., 2015. Transformational change in practice. In: A. Gardiner, M. Bosquet, X. v. Tilburg, N. Harms (Eds.) Annual Status Report on Nationally Appropriate Mitigation Actions (NAMAs) 2015 (pp. 41-42). Patten and Cologne: ECN and Ecofys.

Lütken, S., Dransfeld, B., \& Wehner, S., 2013. Guidance for NAMA design: Building on country experience. Bonn: UN Framework Convention on Climate Change.

Markard, J., Sutera, M., Ingold, K., 2016. Socio-technical transitions and policy change Advocacy coalitions in Swiss energy policy. Environmental Innovation and Societal Transitions 18, 215-237.

Markard, J., Raven, R., \& Truffer, B., 2012. Sustainability transitions: An emerging field of research and its prospects. Research Policy, 41(6), 955-967.

McAlpine, C. A., Seabrook, L. M., Ryan, J. G., Feeney, B. J., Ripple, W. J., Ehrlich, A. H., Ehrlich, P. R., 2015. Transformational change: creating a safe operating space for humanity. Ecology and Society, 20(1), 56-61.

Mersmann, F., Olsen, K. H., Wehnert, T., Boodoo, Z., 2014. Understanding transformational change in NAMAs: From theory to practice. Berlin and Roskilde: Wuppertal Institute for Climate, Environment and Energy \& UNEP DTU.

Mersmann, F., Wehnert, T., Göpel, M., Arens, S., Ujj, O., 2014. Shifting Paradigms: Unpacking Transformation for Climate Action. Berlin: Wuppertal Institute for Climate, Environment and Energy.

ND (NAMA Database). (2014a). Lao PDR: Low Carbon Urban and Housing NAMA. www.nama-database.org/index.php?title=Low_Carbon_Urban_and_Housing_NAMA. Retrieved 21/03/2016.

- (2014b). Costa Rica: Ordinary Solid Waste NAMA. www.namadatabase.org/index.php?title=Ordinary_Solid_Waste_NAMA. Retrieved 21/03/2016.

- (2015a). Bangladesh: Innovative Energy Optimisation in the Steel Sector. www.namadatabase.org/index.php/Innovative_Energy_Optimisation_in_the_Steel_Sector. Retrieved 21/03/2016.

- (2015b). The Gambia: Improved cooking stoves. www.namadatabase.org/index.php/Improved_cooking_stoves. Retrieved 21/03/2016.

- (2015c). Tunisia: Energy conservation in the building sector. www.namadatabase.org/index.php/Energy_conservation_in_the_building_sector. Retrieved 21/03/2016.

- (2015d). Barbados: NAMA in renewable energy and energy efficiency. www.namadatabase.org/index.php/NAMA_in_renewable_energy_and_energy_efficiency. Retrieved 21/03/2016.

NR (NAMA Registry). NS-48. Cook Islands: Supporting Implementation of 100\% Renewable Electricity by 2020. www4.unfccc.int/sites/nama/_layouts/un/fccc/nama/NamaSeekingSupportForImplemen tation.aspx?ID=35. Retrieved 21/03/2016. Retrieved 21/03/2016.

- NS-71. Costa Rica: Costa Rica Livestock NAMA. www4.unfccc.int/sites/nama/_layouts/un/fccc/nama/NamaSeekingSupportForImplemen tation.aspx?ID=91. Retrieved 21/03/2016.

- NS-72. Costa Rica: NAMA - Low Carbon Coffee - Costa Rica.

www4.unfccc.int/sites/nama/_layouts/un/fccc/nama/NamaSeekingSupportForImplemen tation.aspx?ID=90. Retrieved 21/03/2016. 
— NS-85. Georgia: Adaptive Sustainable Forest Management in Borjomi-Bakuriani. www4.unfccc.int/sites/nama/_layouts/un/fccc/nama/NamaSeekingSupportForImplemen tation.aspx? ID=52. Retrieved 21/03/2016.

— NS-201. Tunisia: NAMA Support for the Tunisian Solar Plan. www4.unfccc.int/sites/nama/_layouts/un/fccc/nama/NamaSeekingSupportForImplemen tation.aspx? ID=128. Retrieved 21/03/2016.

— NS-226. The Gambia: Rural Electrification with Renewable Energy in The Gambia. www4.unfccc.int/sites/nama/_layouts/un/fccc/nama/NamaSeekingSupportForImplemen tation.aspx?ID=152. Retrieved 21/03/2016.

- NS-227. Lao PDR: NAMA for Rural Development in Lao PDR. www4.unfccc.int/sites/nama/_layouts/un/fccc/nama/NamaSeekingSupportForPreparatio n.aspx?ID=153. Retrieved 21/03/2016.

- NS-228. Georgia: Energy Efficient Refurbishment in the Georgian Public Building Sector. www4.unfccc.int/sites/nama/_layouts/un/fccc/nama/NamaSeekingSupportForImplemen tation.aspx? ID=158. Retrieved 21/03/2016.

- NS-229. Georgia: Efficient use of biomass for equitable, climate proof and sustainable rural development.

www4.unfccc.int/sites/nama/_layouts/un/fccc/nama/NamaSeekingSupportForImplemen tation.aspx?ID=154. Retrieved 21/03/2016.

Raven, R., Bosch, S. v. d., Weterings, R., 2010. Transitions and strategic niche management: towards a competence kit for practitioners. Int. J. Technology Management, 51(1), 5774.

Scoones, I., Leach, M., Newell, P. (Eds.), 2015. The Politics of Green Transformations. Abingdon and New York: Eartschan.

Sharma, S., Desgain, D. D. R., 2013. Understanding the Concept of Nationally Appropriate Mitigation Action. Copenhagen: UNEP DTU.

Shrivastava, M. K., Upadhyaya, P., 2014. Whither Multilateralism? Implications of Bilateral NAMA Finance for Development and Sovereignty Concerns of Developing Countries. Paper presented at the Development and Mitigation Forum, Cape Town, 27-29 January 2014.

TND (Transport NAMA Database). (n.d.1). Lao PDR: Master Plan on Comprehensive Urban Transport of Vientiane (Laos). www.transport-namadatabase.org/master-plan-oncomprehensive-urban-transport-of-vientiane-lao. Retrieved 21/03/2016.

- (n.d.2). Bangladesh: NAMA Proposal for the railway sector in Bangladesh. www.transport-namadatabase.org/nama-proposal-for-the-railway-sector-in-bangladesh. Retrieved 21/03/2016.

Tyler, E., Boyd, A., Coetzee, K., Gunfaus, M. T., Winkler, H., 2013. Developing country perspectives on 'mitigation actions', 'NAMAs', and 'LCDS'. Climate Policy, 13(6), $770-776$.

UNFCCC, 2007. COP13: Addendum 1 to report (including the Bali Action Plan), Bali 2007. FCCC/CP/2007/6/Add.1. Bonn: UN Framework Convention on Climate Change.

UNFCCC. (2011). COP16: Addendum 1 to report, Cancún 2010. FCCC/CP/2010/7/Add.1. Bonn: UN Framework Convention on Climate Change.

UNFCCC, 2016. COP21 report (addendum 1), Paris 2015. FCCC/CP/2015/10/Add.1. Bonn: UN Framework Convention on Climate Change.

van der Laak, W. W. M., Raven, R. P. J. M., Verbong, G. P. J., 2007. Strategic niche management for biofuels: Analysing past experiments for developing new biofuel policies. Energy Policy, 35(6), 3213-3225. 
van Tilburg, X., Würtenberger, L., de Coninck, H., Bakker, S., 2011. Paving the way for lowcarbon development strategies. Patten: Energy Research Centre.

Winkler, H., 2014. Emerging lessons on designing and implementing mitigation actions in five developing countries. Climate and Development, 6(S1), 1-3.

Winkler, H., Dubash, N. K., 2015. Who determines transformational change in development and climate finance? Climate Policy (online first, doi:10.1080/14693062.2015.1033674), 1-9.

World Bank. (2016). World Bank Open Data on income. Retrieved 05/07/2016 from http://data.worldbank.org/data-catalog/GNI-per-capita-Atlas-and-PPP-table. 